\title{
Participação Comunitária e Identidade Territorial na Gestão de Museus: A Mobilização Museológica Organizacional e Interorganizacional
}

Hilda Bárbara Maia Cezário ${ }^{1}$

Eduardo Davel ${ }^{2}$

\begin{abstract}
Resumo
Este artigo propõe estratégias de gestão para iniciativas museológicas comunitárias com base na participação e na identidade territorial como fatores substantivos a essas iniciativas e mobilizadores da sua dimensão organizacional e interorganizacional. A mobilização museológica organizacional parte do entendimento da organização como processo, que busca interligar as 'áreas fins' do museu (ligadas, especificamente, às funções museológicas) às 'áreas meio' (ligadas às atividades administrativas e gerenciais), através de estratégias de ação desenvolvidas no âmbito interno do museu, possibilitando uma visão mais completa e gerencial da organização. Já a mobilização museológica interorganizacional refere-se ao potencial de relações externas ao museu, seja através de parcerias ou do trabalho em rede, a partir da cooperação entre organizações, propiciada pelo compartilhamento de uma identidade territorial comum e pela dinâmica participativa. A partir da abordagem qualitativa, da análise documental e dos estudos de diferentes museus, dentro e fora do Brasil, os resultados desta pesquisa (estratégias de gestão), de vocação tecnológica, auxilia líderes comunitários, gestores sociais e empreendedores culturais de comunidades na gestão de museus com base na participação comunitária e na identidade territorial. Consequentemente, torna-se
\end{abstract}

\footnotetext{
${ }^{1}$ Museu do Traje, São Brás de Alportel, Portugal hbarbaramaia@gmail.com

Escola de Administração, Universidade Federal da Bahia, Brasil Davel.eduardo@gmail.com
} 
relevante para a formação em museologia e em gestão social, bem como para o norteamento dos poderes públicos em relação ao papel da gestão no desenvolvimento de museus comunitários.

Palavras-chave: Gestão de museus comunitários; organização; interorganizações; participação; identidade territorial.

\begin{abstract}
This article proposes management strategies for museological community initiatives based on participation and territorial identity as key factors to these initiatives and mobilizers of their organizational and inter-organizational dimension. The organizational mobilization starts from the organization's understanding as a process that seeks to connect the 'functional areas' of the museum (linked, specifically, to museological functions) to the 'managerial areas' (related to management activities) by developing action strategies on internal museum context, enabling a more complete and managerial vision of the organization. The inter-organizational mobilization refers to the potential for external relationships, either through partnerships or a networking, but also through the cooperation between organizations that share the territorial identity and the dynamics of participation. From the qualitative approach, document analysis and studies of different museums, national and international ones, the research outcomes (management strategies), with technological vocation, helps community leaders, social managers and cultural entrepreneurs of communities to better manage museums based on community participation and territorial. It also helps in the training for social museology and management. Consequently, it becomes relevant for guiding public policies in relation to the role of the management in the development of community-based museums.
\end{abstract}

Keywords: community museum management; organization; interorganizations; participation; territorial identity.

\title{
Introdução
}

Este artigo propõe a mobilização museológica organizacional e a mobilização museológica interorganizacional como conjuntos de estratégias de gestão para iniciativas museológicas comunitárias, tendo como fatores mobilizadores a 
identidade territorial e a participação comunitária, elementos substantivos a esta tipologia de equipamento. Para compreender as mobilizações propostas é preciso definir o que se entende por iniciativa museológica comunitária, bem como os conceitos que sustentam os elementos destacados como potenciais para a sua própria mobilização. Estas iniciativas referem-se a experiências provenientes da Museologia Social, da adoção do museu como processo, vivenciado a partir de ações coletivas transformadoras, em que os sujeitos são capazes de manejar seus referenciais de patrimônio, identidade e memória por meio de uma metodologia de trabalho participativa e dialógica, colocando-se a serviço do desenvolvimento de um território sustentável (Lersch \& Ocampo, 2004, 2009; Priosti \& Mattos, 2007; Varine-Bohan, 2013; Ibram, 2016).

A Museologia Social é considerada como um resultado da Nova Museologia, corrente de reflexões que ganhou corpo na área dos museus a partir da década de 1970, com o questionamento sobre a função social destes equipamentos, consolidando-se na década de 1980, com o Movimento Internacional da Nova Museologia - MINOM (Chagas \& Gouveia, 2014; Moutinho, 1993, 2007; Priosti, 2010; Santos, 2008). Atualmente, a Museologia Social, tal qual é difundida no Brasil, ou Sociomuseologia, como é largamente utilizada na Europa, principalmente em Portugal, pode ser compreendida como uma museologia centrada na dimensão local, com objetivo de reforçar os processos coletivos de definição de identidades, autoconhecimento e pensamento crítico, comprometidos com a construção dos sujeitos a partir da memória e do patrimônio (Sancho-Querol \& Sancho, 2015, p. 215-216).

A identidade territorial e a participação são essenciais para a existência das iniciativas museológicas comunitárias. São fatores que serão tomados como verbo, através de estratégias de ações mobilizadoras de cada dimensão em si. Consideramos a mobilização como o ato ou efeito de fazer pessoas entrar em 
campanha, acionando-as, ativando interesses e incitando à participação. Como metáfora, os fatores mobilizadores são a faísca que acende o potencial organizativo e interorganizacional para o desenvolvimento do museu, com vistas a uma gestão sustentável.

A mobilização museológica organizacional refere-se à compreensão do museu como organização em sua totalidade, levando em consideração as especificidades de suas atividades "fins", relacionadas, especificamente, às funções museológicas básicas ${ }^{3}$, como também as atividades "meio", relacionadas às suas necessidades administrativas e gerenciais que oferecem o suporte preciso para a ação museológica. Logo, o maior potencial desta mobilização é a promoção de uma visão ampla e complexa do museu, entendendo-o como sistema que depende do "conjunto de procedimentos metodológicos, infraestrutura, recursos humanos e materiais, técnicas, tecnologias, políticas, informações, procedimentos e experiências necessários para o desenvolvimento de processos museais" (Cury, 2010, p.273).

Enquanto a mobilização organizacional volta-se para esta compreensão sistêmica do museu como um organismo em si, a mobilização museológica interorganizacional volta-se para o potencial deste organismo em interação com o mundo. A mobilização interorganizacional envolve a relação com outras organizações, de forma consciente, no que ativa o potencial das parcerias e da atuação em redes de cooperação sobre um determinado território. Dessa forma, constitui-se um "tecido híbrido formado por organizações que atuam em conjunto" (Fischer \& Melo, 2004, p.18), sob um objetivo específico.

\footnotetext{
${ }^{3}$ Adota-se para este trabalho o sistema PPC (pesquisa-preservaçãocomunicação) da Reinwardt Academie de Amsterdam (Desvallées \& Mairesse, 2013). A dinâmica deste sistema compõe o processo museológico, caracterizado também como um processo educativo (Santos, 2008), ou seja, a educação não é pensada como um elemento entre os outros três, mas um fator que perpassa transversalmente a dinâmica museológica.
} 
Ressalta-se que em um cenário de escassez de recursos, como geralmente é o caso dos museus no Brasil, sobretudo os públicos e de pequeno porte, as parcerias e ações interorganizacionais viabilizam a dinamização e a sustentabilidade do museu. Entretanto, essas ações, geralmente, não são sistematizadas e o potencial interorganizacional fica apenas como uma estratégia pontual para determinado projeto.

Dentro desse panorama de necessidades organizacionais e interorganizacionais, este artigo busca contribuir com a prática dos museus comunitários, produzindo um saber com relevância prático-profissional. Por conseguinte, o objetivo da pesquisa é propor estratégias de gestão que atuem na 'ativação' destas mobilizações, levando em consideração tanto práticas participativas, quanto atividades provocadoras de interfaces das identidades de determinado grupo, com vistas a uma possível identidade territorial compartilhada.

Na perspectiva destes museus, a participação é tida como princípio no processo contínuo do "fazer museu" (Moutinho, 2007; Sancho-Querol, 2016) e refere-se a um processo ativo da comunidade, na medida em que há algum nível de poder cidadão, ou seja, "poder real para influenciar os resultados do processo" (Arnstein, 2002, p.2). Este nível de participação é possível tanto através de práticas de controle total por parte do cidadão ou da autogestão do museu, quanto da delegação de poder e do exercício da participação representativa, tal qual em nossa democracia, ou ainda, através de parcerias, em que o resultado trata-se de uma negociação de igual para igual, sem prevalecer os interesses de uns em detrimento dos demais.

O território é entendido como 'espaço socialmente construído' (Lefebvre, 2000; Santos, 2000) e a identidade enquanto 'prática social' (Holland et al., 1998), compreendida como processo tal qual o próprio museu (Canclini, 2003; Craib, 1998), vista de forma fragmentada e, por vezes, apresentada através de múltiplos fragmentos (Hall, 2006) derivados de 
inúmeros fatores, seja das relações simbólicas (culturais) como também das relações de poder (políticas), levando em consideração todos os aspectos do seu território (Saquet \& Briskievicz, 2009), tomando-o como dimensão crucial para o seu florescimento (Davel et al., 2016).

Parte-se da compreensão de que para uma gestão sustentável do museu, faz-se necessário integrar essas dinâmicas culturais da comunidade, através da participação, aos seus processos organizacionais, de forma sistêmica, consciente e sensível às mudanças que vão ocorrendo, bem como à diversidade identitária do território (Dessein et al., 2015), atentando-se para os potenciais interorganizacionais possíveis. Com base neste contexto e entendimento dos conceitos enunciados, é que se propõe estratégias de gestão em ambas as dimensões - organizacional e interorganizacional, integrando uma tecnologia social mais ampla de gestão de iniciativas museológicas comunitárias (Cezário et. al., 2017, 2018; Cezário \& Davel, 2017, 2018).

A reflexão e proposição das estratégias presentes neste artigo é motivada pela constatação da escassez de materiais referentes à gestão destes tipos de museus. A pouca produção evidenciada, em sua maior parte, por manuais práticos (Fopp, 1997; Genoways \& Ireland, 2003; Lord \& Lord, 2005; Mason, 2004; Boylan, 2004; Davies, 2001), trata de forma pragmática o gerenciamento de espaços físicos, de acervos, equipes e recursos financeiros, a partir de uma perspectiva da administração clássica. Produções mais recentes (Cândido, 2013, 2014) revelam além de uma sistematização minuciosa destes manuais de gestão, o aprofundamento de algumas questões e uma reflexão sobre o desenvolvimento do diagnóstico e do planejamento museológico, tratando, portanto, de procedimentos apropriados, especificamente, para a gestão de museus. Todavia, a lacuna ainda é maior quando se trata de processos de gestão para esta tipologia de museu, que considere plenamente a identidade 
territorial e, sobretudo, a participação, que é um princípio para estas organizações e, logo, deveriam ser tratados como fatores imprescindíveis para pensar a sua gestão.

Parte-se, também, do entendimento de que o caráter dinâmico destas iniciativas, por vezes identificadas como "museu processo" ou "museu vivo" (Varine-Bohan, 2012, 2014; Santos, 2008; Priosti, 2010), com frequência é utilizado de forma equivocada para justificar incongruências decorrentes de uma gestão não coesa com os princípios dessas organizações. Isso é muito comum quando essas experiências fragilizadas, com pouco engajamento, sem representatividade social, que podem ser devido a inúmeros fatores, apontam como causa deste definhamento apenas a própria dinâmica cultural local. Sem desconsiderar esta possibilidade, problematiza-se essa decadência e, até mesmo, o desaparecimento destes museus, que ao longo do tempo, acabam por se tornarem cada vez mais similares aos museus ditos tradicionais (Scheiner \& Brulon Soares, 2009), e levanta-se a questão: seria a dinâmica cultural a maior ou a única responsável? Ou a falta de gestão adequada aos princípios da Museologia Social poderia ser um outro fator significativo?

A partir destes questionamentos, entendemos que boa parte desta decadência pode ser atribuída a ausência de uma gestão adequada para este tipo de equipamento, portanto, trabalha-se a ideia de que a iniciativa museológica comunitária necessita ser compreendida enquanto uma organização. Trata-se de uma "organização como processo" e não como "entidade pronta" (Davel \& Vergara, 2005, p.11), que demanda o entendimento de uma ordem social própria que estrutura o seu sistema de atividades (França Filho, 2004) também com processos próprios, e que, portanto, devem ser diferenciados da forma de organização e gestão de um museu tradicional.

As estratégias apresentadas neste artigo podem ser resumidas pela interação entre a mobilização museológica 
organizacional e interorganizacional, perpassando a compreeensão do museu enquanto organização-processo, que demanda (a) a construção de uma identidade organizacional e (b) o gereciamento coletivo de seus mecanismos de operacionalização das ações; e chegando à interação deste museu-processo com outras organizações no território, sejam organizações não governamentais e populares, públicas ou privadas (Figura 1).

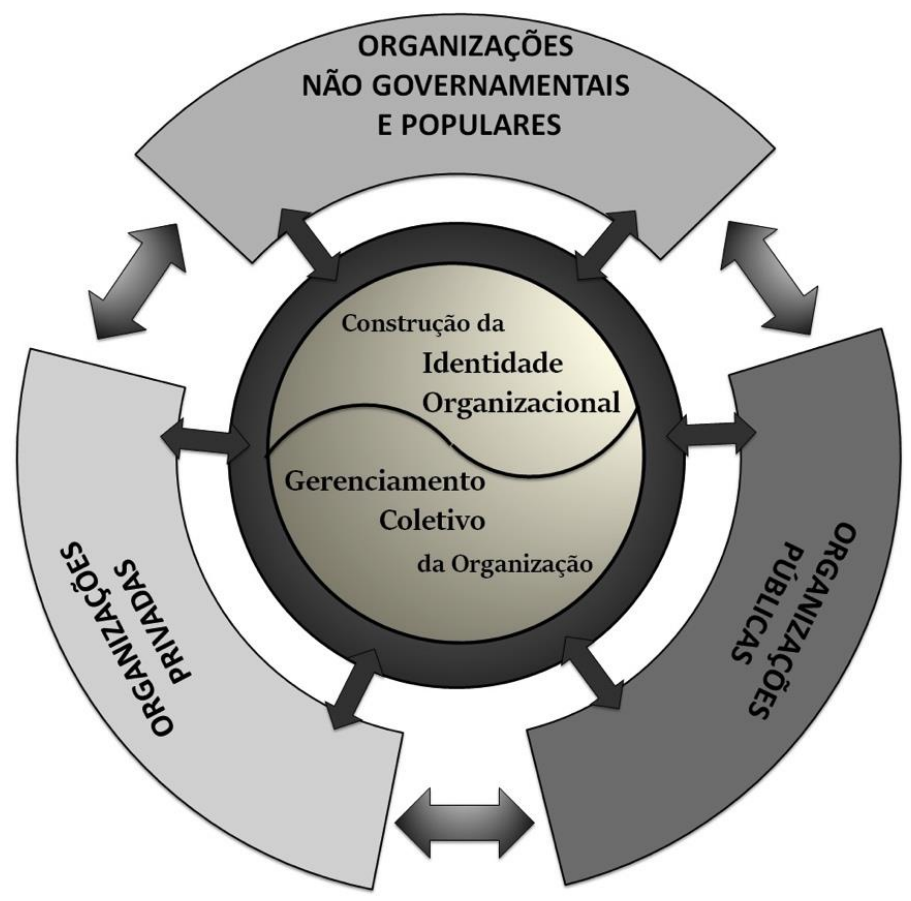

Figura 1 - Interação entre Mobilização Museológica Organizacional e Interorganizacional

Fonte: Elaboração própria (2017).

No plano metodológico, a pesquisa teve uma abordagem qualitativa, destacando o uso do estudo de casos múltiplos, 
sendo um caso holístico (o Museu do Alto Sertão da Bahia MASB, sediado em Caetité-BA), estudado de forma global, e outros três casos integrados (o Museu do Traje de São Brás de Alportel - MuT, em Portugal, o Ponto de Memória Tia Dina em Matarandiba, Ilha de Itaparica-BA e o Ecomuseu de Santa Cruz no Rio de Janeiro - RJ) examinados apenas por focos de investigação (Yin, 2010).

O MASB é um museu de território, polinucleado, com sede no município de Caetité, e 10 núcleos pelo território, englobando também os municípios vizinhos de Guanambi e Igaporã. Fruto de uma iniciativa comunitária em 2011, o museu hoje possui uma estrutura de gestão complexa que envolve a tutela jurídica do município de Caetité, a tutela técnica da Universidade do Estado da Bahia, Campi VI e XII, e a Associação de Amigos do MASB (AMASB), responsável maior pela gestão dos seus recursos. Além disso, desde os primeiros passos o museu conta com o apoio da Renova Energia, sendo até o momento o principal parceiro financiador. O museu permanece em contínua articulação para o envolvimento dos demais poderes públicos e outros parceiros no território.

O MuT localiza-se na vila de São Brás de Alportel, na região do Algarve, sul de Portugal. A mobilização comunitária a partir da iniciativa local de um pároco no início da década de 1980 deu surgimento ao museu, que hoje é vinculado à Santa Casa de Misericórdia, que lhe provém de um espaço próprio, diretor e uma equipe reduzida de funcionários. Entretanto, conta com colaboradores voluntários que contribuem para a dinâmica do museu, integrados em diversos grupos, tais como os Amigos do Museu e o Clube do Museu. Mais informações: http://museusbras.com/.

Já o Ponto de Memória Tia Dina é um museu comunitário gerido pela Associação Sócio Cultural de Matarandiba (ASCOMAT), oficialmente criado em 2012, quando a Associação recebeu o prêmio pelo Programa Pontos de Memória do Instituto 
Brasileiro de Museus (IBRAM), por se destacar como uma iniciativa relevante no contexto nacional pelo trabalho com o patrimônio cultural e a memória da pequena vila com aproximadamente 900 habitantes (Machado, 2013). O museu, compreendido como parte da atuação da ASCOMAT que também envolve outras iniciativas locais, depende da estrutura de gestão desta organização e da mobilização de voluntários da comunidade local. O mesmo ainda não possui página virtual.

Por fim, o Ecomuseu de Santa Cruz, oficialmente designado Ecomuseu do Quarteirão Cultural do Matadouro de Santa Cruz em 1995 pela Secretaria Municipal de Cultura do Rio de Janeiro, também configura-se como um museu de território que engloba vários pontos do bairro de Santa Cruz, na zona oeste da cidade do Rio de Janeiro. O museu tem origem nas ações do Núcleo de Orientação e Pesquisa Histórica (NOPH), organização que desde 1983 já mobilizava a comunidade do bairro frente à necessidade de preservação e valorização do patrimônio e da memória local (Priosti, 2010). Mais informações:

http://www.ecomuseusantacruz.com.br

Para a abrangência do estudo de casos múltiplos adotou-se um desenho metodológico envolvendo três fases, baseadas nas seguintes técnicas de coletas de dados: documentos, observação e entrevistas. A primeira Fase 1 era focada na revisão de experiências documentadas, tanto no que se refere à gestão de museus como a gestão de projetos sociais. Para o levantamento de informações nesta etapa a pesquisa se concentrou em documentos e em entrevistas semiestruturadas com profissionais e pesquisadores do campo da Museologia Social no Brasil e no exterior, com objetivo de identificar experiências significativas, assim como a própria relevância do estudo proposto e a indicação de materiais de pesquisa. Tratou-se de uma sondagem do campo, de forma mais fluida e menos sistêmica. Já a Fase 2 foi dedicada ao estudo de caso holístico com o Museu do Alto Sertão da Bahia. A coleta de dados teve por base documentos, 
entrevistas e observação participante direta, considerando as informações provenientes dos treze meses de atuação efetiva da pesquisadora nos processos do museu. Desta forma, a coleta envolveu desde documentos já produzidos pelo museu, tais como Plano Museológico e até mesmo o Estatuto da Associação de Amigos do MASB que surge em paralelo, até as atas de reuniões e trocas de mensagens entre o grupo gestor, do qual a pesquisadora foi partícipe. Por fim, a Fase 3 foi dedicada aos casos integrados já enunciados, englobando documentos de referência produzidos e cedidos pelas respectivas instituições (regimentos internos, comunicações, produções acadêmicas, etc.), bem como a realização de entrevistas semiestruturadas com lideranças locais e com lideranças dos museus elegidos. Destaca-se, entretanto, a coleta de dados também através da observação participante direta realizada pela pesquisadora em campo excepcionalmente no caso do Museu do Traje de São Brás de Alportel, em Portugal, onde esteve inserida na dinâmica organizacional durante 20 dias da pesquisa.

A análise de narrativa (Gubrium \& Hostein, 2009; Maitlis, 2012; Riessman, 2008) do material empírico foi estruturada em torno do processo de mobilização organizacional e interorganizacional, em relação aos princípios de identidade territorial e participação comunitária. Pela variedade de categorias emergentes da análise, pela riqueza de detalhes, pela busca de relevância prática deste artigo, não é possível expor as narrativas dos participantes da pesquisa, uma vez que, isso ultrapassaria o tamanho do artigo e/ou reduziria o escopo de ideias que apresentamos. Portanto neste artigo, expõe-se muitas propostas e interpretações, mas não se fornece muitos detalhamentos empíricos, de modo que uma visão de conjunto seja viável (dentro do escopo de um artigo). As propostas são elaboradas a partir de uma análise sistemática, relacionando o material empírico (documentos, entrevistas, observação) com a teoria (gestão de museus, museus comunitários e gestão). 
Estruturado em três grandes seções, além desta introdução e da conclusão, este artigo apresentará, inicialmente, a mobilização museológica organizacional, detalhando o seu entendimento e apresentando de forma sistematizada os conteúdos necessários para a execução de algumas estratégias de gestão em suas subseções, indicando referencias e material para aprofundamento. Na segunda seção, seguindo a mesma lógica, apresentamos a mobilização museológica interorganizacional. A terceira seção aborda as discussões e impactos desta pesquisa para o campo teórico e prático da museologia social e da gestão social.

\section{A Mobilização Museológica Organizacional}

Ao considerar uma mobilização organizacional como estratégia de gestão para uma iniciativa museológica comunitária, evidencia-se a necessidade de pensar o museu como uma organização. Entretanto, é preciso destacar o que se entende por organização, uma vez que, o conhecimento comum, com base em anos de teoria e prática de uma visão sistêmicocontroladora, tende a relacionar organização a uma entidade fixa, homogênea e estável. Porém, para efeitos deste trabalho, adotase a visão processual- relacional, que aborda a organização como processo, tomada como verbo, de forma que possa ser melhor compreendida como uma construção contínua do ato de organizar, buscando agregar seus diversos elementos (Watson, 2005; Duarte \& Alcadipani, 2016; Davel \& Vergara, 2005, Czarniawska, 2008; Hosking \& Fineman, 1990).

Uma inciativa museológica comunitária apresenta um caráter duplamente processual, considerando que: (a) enquanto tipologia museológica, ela é concebida como processo do se 'fazer museu', e (b) enquanto organização social, ela é compreendida no contínuo processo de estabelecimento de "relações organizadoras" (Watson, 2005). Logo, o entendimento organizacional "implica o reconhecimento e a identificação de 
suas diferentes dimensões ou variáveis constitutivas" (França Filho, 2004, p. 40), para uma gestão mais complexa e relacional. Assim sendo, essas concepções convergem para o propósito maior desta mobilização, que consiste em construir um ambiente organizacional coeso a partir de um projeto de gestão que tenha em vista o imbricamento existente entre essas diferentes dimensões ou variáveis constitutivas, "de modo a operar com eficiência as atividades meio com as atividades fim" do museu (Cury, 2010, p. 274).

Assim, a mobilização museológica organizacional propõe estratégias de gestão direcionadas para essas variáveis constitutivas da organização, seja relacionada ao seu próprio modelo de gestão, a estrutura organizacional, a comunicação, a memória e a identidade desta organização evidenciada por sua visão, imagem e cultura, bem como por fatores gerenciais de ordem mais prática, como o gerenciamento de equipe, de espaço e de captação de recursos e financiamentos. A gestão, nesta perspectiva, é entendida como uma dessas variáveis organizacionais, porém apresenta papel central em relação às demais, pois possui o potencial de articular todas as outras para o funcionamento da organização.

As estratégias de gestão em questão expressam a coerência da dinâmica organizacional do museu. Dessa forma, entender a organização como potencial de mobilização exige, antes de tudo, ter por base a identidade territorial e a participação comunitária, fatores que sustentam os vínculos que dão origem e perenidade ao museu, como fatores transversais da iniciativa museológica. Busca-se aproximar e valorizar o trabalho do museu para aquilo que lhe é central - a comunidade em determinado território.

Portanto, os esforços entre área meio e área fim se somam e são potencializados, mas devem evitar o antagonismo. Por exemplo, a identidade territorial nestes contextos se fragiliza ao se limitar a apenas um assunto de um setor específico do museu, 
como geralmente é feito, atribuída como uma responsabilidade a ser trabalhada na exposição ou através de outras ações educativas. A integração e visão de conjunto é fundamental. Apesar da atividade museológica de construção da exposição do museu prever ações que evidenciem a identidade territorial e suas múltiplas questões, esta mesma atividade poderá ser útil para o tratamento da comunicação institucional do museu, reverberando a sua identidade organizacional perante toda a comunidade.

Esta mobilização tem papel norteador e organizativo, a partir de duas dimensões organizacionais com atividades e práticas correlatas - a dimensão da identidade organizacional e a dimensão do gerenciamento coletivo. Pretende-se o entendimento do museu como um todo e oferece à gestão um maior potencial de ação, uma vez que, compreendendo como seu trabalho pode contribuir para a formação da organização e entendendo esta como processo (Davel \& Vergara, 2005, p.11), as figuras de gestão "podem promover a evolução do aprendizado e de competências gerenciais por meio da construção de significados, negociações e barganhas, e do exercício do poder" (Watson, 2005, p.14).

\subsection{Construindo a Identidade Organizacional com base na Participação Comunitária e na Identidade Territorial}

Seja em uma iniciativa museológica comunitária já existente ou em um processo de concepção inicial de um museu comunitário, a construção da identidade organizacional deste equipamento necessita, em primeira instância, da constituição do grupo por trás desta 'vontade de museu' (Chagas, 2007). Este coletivo, ainda que seja formado por pessoas "flutuantes" (que participam conforme interesse e disponibilidade, e não mantenham uma periodicidade constante), é o primeiro passo para a própria constituição do museu. 
A associação destes atores sociais locais por meio de encontros presenciais, em redes e mídia digitais, já é indício de entendimento, valores, artefatos e símbolos comuns, ou seja, do compartilhamento de componentes de uma dinâmica cultural (Hatch, 1993). Entretanto, para o desenvolvimento do museu, é necessário mais que isso. Este grupo precisa refletir conjuntamente sobre o que almeja, qual o principal compromisso, objetivos e formas de atuação, definindo uma identidade a partir das possíveis multiplicidades e interfaces identitárias locais. Essa identidade se dá por meio das relações entre indivíduos e organizações, em dado território, também definido por estes atores sociais. A partir desta identidade territorial, o museu conseguirá promover uma identidade organizacional, uma vez que, estas iniciativas não possuem sentido de existência quando descoladas da identidade cultural local ou da identidade territorialmente "construída" por seus coletivos de base.

Dessa forma, busca-se a integração entre identidade territorial e identidade organizacional. Pode-se dizer que a identidade organizacional deve prezar por formas de externar a identidade territorial assumida pelo museu, por meio dos seus diversos componentes. Sendo assim, torna-se necessário o alinhamento entre a cultura organizacional, a visão estratégica da organização e a imagem organizacional, conforme defende Hatch e Schultz (1997, 2008). Consequentemente, cada iniciativa museológica almeja mobilizar todos os seus componentes, de forma a estimular que o maior número de pessoas relacionadas ao museu participe da realização de um exercício, trabalhando os seguintes pontos: (a) quem somos? (cultura organizacional); (b) quem queremos ser e como queremos ser vistos? (visão estratégica organizacional) e, (c) como somos vistos? (imagem organizacional), conforme Figura 2.

Com base neste exercício realizado de forma individual e levado para a discussão no âmbito coletivo da iniciativa do 
museu, cada questão poderá ser discutida, de forma a considerar todos os pontos de vista dos indivíduos, buscando a construção de uma resposta que seja compartilhada pelo grupo. A questão da imagem pode ser levada à comunidade de um modo geral, não se restringindo aos membros integrantes do museu, ou a seus parceiros mais próximos, mas buscando a opinião de grupos no território que talvez não possuam nenhuma interação direta com o mesmo.

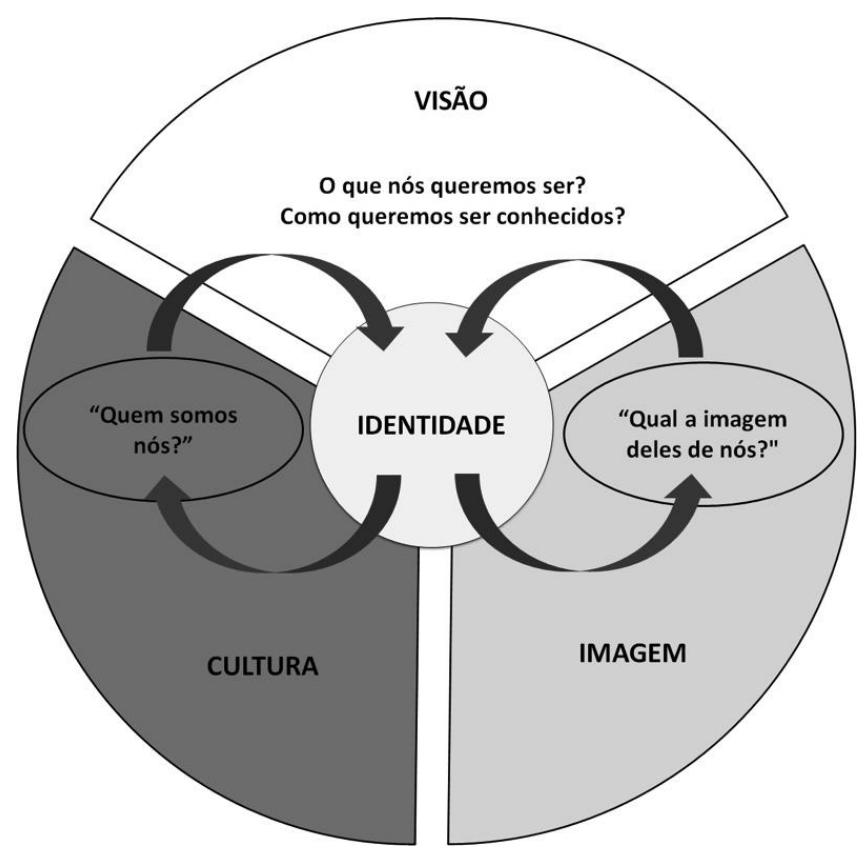

Figura 2 - Dinâmica da Identidade Organizacional proposta por Hatch e Schultz

Fonte: Hatch e Schultz (2008, p. 68).

A partir da análise e reflexão crítica sobre o alinhamento dos três pontos levantados, é possível definir tanto uma cultura como uma visão, além de projetar uma imagem que seja 
condizente e coesa com toda a concepção do museu no território. Não adianta, por exemplo, o museu se dizer comunitário, quando apenas poucas pessoas em determinada comunidade têm abertura para esta participação. De outro lado, não adianta esperar que todas as pessoas de determinado território desejarão e estarão dispostas a trabalhar na causa do museu. Pessoas podem compreender, entender que o museu está aberto a sua participação, mas simplesmente, optar por não participar. Assim, o museu expõe seus propósitos, de forma clara e aberta, possibilitando a inserção daqueles que tenham interesse, em consonância com os seus princípios e valores de base, disseminando esta imagem pelo território, de modo que possa ser assim compreendido mesmo por aqueles que não desejem participar, mas reconheçam que esta é a sua condição sine qua non.

\subsubsection{Realizando o Diagnóstico Organizacional Participativo do Museu}

A horizontalidade dos processos, prevista pelo princípio da participação, contribui para que, por meio da mobilização organizacional, haja a compreensão plena do museu. Isso está intrinsecamente ligado à regulamentação do setor museal vigente no país através da Lei 11.904 de outubro de 2009, que vem instituir o Estatuto de Museus, estabelecendo, dentre outras coisas, que todos os museus devem, obrigatoriamente, apresentar o Plano Museológico - uma ferramenta norteadora de gestão que deve ser construída pelo museu de maneira participativa, porém assinada por um profissional museólogo, levando em consideração não só a equipe, o acervo, a estrutura física, mas também, o território e comunidade com o qual este atua. "O Plano Museológico definirá sua missão básica e sua função específica na sociedade" e é indicado o desenvolvimento e detalhamento dos seguintes programas do museu: Institucional, de Gestão de Pessoas, de Acervos, de Exposições, 
Educativo e Cultura, de Pesquisa, Arquitetônico-urbanístico, de segurança, de Financiamento e Fomento, e de Comunicação (Brasil, 2009).

Ao falar do Plano Museológico, fala-se da principal ferramenta de gestão do museu, que deve provocar o alargamento da visão da gestão museológica, relacionando a dita 'área meio' com suas 'áreas fins'. Dessa forma, busca-se romper com esta dissociação muito forte na área cultural como um todo, construindo uma organização mais coesa e dinâmica, contando com a construção de uma identidade organizacional fortalecida através da mobilização da participação e da identidade territorial em todo o âmbito organizacional do museu.

Entretanto, para o desenvolvimento do Plano Museológico exigido oficialmente às instituições museais, é necessário, primeiro, a realização de um 'Diagnóstico Organizacional Participativo', referenciado também por Diagnóstico Museológico como etapa fundamental do planejamento e da gestão de qualquer organização, seja esta em criação ou já existente, "uma análise global e prospectiva da instituição (...). O interesse é o museu como um todo. Este diagnóstico considera alguns de seus aspectos amplos como a gestão e também outros setores, podendo ser aprofundado em diagnósticos específicos" (Cândido, 2014, p. 14).

Antes de dar início à realização do diagnóstico indica-se a importância de toda a equipe do museu ter conhecimento do que consiste a proposta de trabalho, possibilitando condições concretas para a sua construção participativa desde o início. É necessário, também, um alinhamento de perspectiva para essa avaliação organizacional mais profunda, de forma que todos tenham compreensão de quando se analisa a forma e quando se analisa conteúdo, por exemplo. A análise da organização pressupõe a escolha e explicitação de um referencial para o que se define como museologia e como deve ser a atuação do museu pelo grupo (Cândido, 2014). Por isso, compreender os princípios 
base de um museu que se propõe comunitário, retomando as referências da Museologia Social, se torna tão importante. Após estes esclarecimento e definições, cabe ao grupo a avaliação das formas possíveis para a realização do diagnóstico e planejamento museológico, tendo em vista a necessidade de participação do maior número de pessoas envolvidas na organização. Esta ação demandará o acompanhamento de profissional adequado para mediação e a disponibilidade de tempo do coletivo.

\subsubsection{Estabelecendo o Modelo e a Estrutura Organizacional}

O modelo e a estrutura organizacional de gestão adotados pela iniciativa podem tanto ser um fiasco, como podem provocar mudanças substanciais no seu cotidiano organizacional e territorial, ao levar em conta os seus fatores mobilizadores já evidenciados. "Os elementos de uma estrutura devem ser selecionados para alcançar uma congruência interna ou harmonia, bem como uma congruência básica com a situação da organização" (Mintzberg, 1995, p.10). Com efeito, a estrutura organizacional refletirá de modo coerente as características da organização, tanto internas como externas, perpassando da missão e dimensão da atuação ao ambiente e atores sociais envolvidos, englobando assim, as características territoriais também. Um museu comunitário que adota uma gestão totalmente hierarquizada e centralizadora fere o seu princípio base de participação, incorrendo num fracasso do modelo organizacional não condizente com o caráter processual próprio desta iniciativa.

O caráter processual e participativo do museu não deve ser desculpa para a ausência de mecanismos de operacionalização do trabalho. A iniciativa não pode permanecer em uma assembleia constante, excluindo os mecanismos de representação, pois acaba se autoconsumindo, sem o devido encaminhamento das suas ações, uma vez que 'tudo é de responsabilidade de todo mundo' e nunca se sabe, portanto, quem vai desenvolver o quê 
para a construção efetiva do museu. É o próprio grupo que vai "decidir, participativamente, quando tais ou quais membros devem participar ou não, em qual atividade, e quais os assuntos devem ser objetos da consulta geral ou somente objeto da decisão por um grupo delegado" (Bordenave, 1983, p.80). Logo, potencializa-se o poder gerencial da assembleia (não descartada), de forma a permitir a autonomia aos seus membros dentro dos horizontes previamente estabelecidos pelo grupo. Dentre estes horizontes, busca-se destacar a própria configuração coletiva da estrutura organizacional, tendo em vista que, esta "envolve duas exigências fundamentais: a divisão do trabalho em diferentes tarefas e a consecução da coordenação entre tais tarefas" (Mintzberg, 1995, p.11).

O grande desafio, portanto, é definir o mecanismo de coordenação que se ajusta à organização da iniciativa, e ao qual se relaciona também os aspectos de comunicação e controle ${ }^{4}$. Uma ação importante é a definição da estrutura organizacional, compreendendo a organização enquanto processo. Podemos citar Mintzberg (1995) para abordar as categorias da estrutura organizacional, mesmo que este autor não compartilhe de uma abordagem processual da organização. Por outro lado, evidencia pelo menos cinco mecanismos de coordenação das tarefas, que funcionam como elementos de coesão da organização, são eles: o ajustamento mútuo, a supervisão direta, a padronização dos processos de trabalho, a padronização dos resultados e a padronização das habilidades dos trabalhadores. O importante é encontrar a relação direta e potencial que esses elementos encontram para a organização do trabalho nesta tipologia de museu, não excluindo a possibilidade de incidência e uso dos demais.

\footnotetext{
${ }^{4}$ Controle aqui é compreendido a partir do paradigma processual-relacional da organização, em que o gestor não possui controle absoluto, porém necessita uma ação de gerencia com controle parcial, um "nível de certeza administrável", para que não haja o caos (Watson, 2005, p.20).
} 
O primeiro elemento, o ajustamento mútuo, é ligado a estruturas informais de organização, pois consiste na coordenação do trabalho pelo processo simples de comunicação informal. O segundo, a supervisão direta, refere-se à coordenação que ocorre por meio de uma pessoa como responsável pelo trabalho de outras, com a tarefa de dar instruções e monitorar ações, geralmente, ligada a estruturas organizacionais formais. Em tese, poderia se dizer, portanto, que uma estrutura organizacional formal não seria condizente com um museu-processo, tendo em vista que a supervisão direta em nada tem a ver com a proposta participativa, com foco na construção de cidadãos autônomos.

Entretanto, Mintzberg (1995, p. 17) observa que, há mais de uma década atrás, pesquisas afirmavam que "estruturas formais e informais são entrelaçadas e muitas vezes impossíveis de ser distinguidas". Dessa forma, a iniciativa museológica comunitária pode se apresentar enquanto instituição formal, com constituição de pessoa jurídica ou atrelada a pessoa jurídica já formalizada, seja ela pública ou privada sem fins lucrativos. Mas, pode também se constituir de modo informal, através de grupos associados como movimentos e coletivos, porém sem a constituição de pessoa jurídica para respaldar o desenvolvimento das ações do museu.

Tanto uma opção quanto a outra possui suas vantagens e seus inconvenientes. O fundamental em todas as formas possíveis é a existência de espaços que possibilitem a participação comunitária, entendendo que estes vão além de processos consultivos. São espaços que garantem processos de participação cidadã plena, em que os sujeitos sejam ativos e disponham de poder real para influenciar os resultados do processo que estão envolvidos (Arnstein, 2002). Para tal, o próprio processo do museu deve estar imbuído do compromisso social de formação cidadã, de modo que todos os sujeitos possam ser capazes de refletir criticamente sobre a realidade e os 
propósitos de suas ações e das ações dos demais atores sociais sobre si (Priosti, 2010; Varine-Bohan, 2013). Dessa forma, somente sob a premissa da participação é que se faz possível o desenvolvimento do museu comunitário, caso contrário, outro tipo de museu ou organização pode vir a surgir.

A formalização organizacional não implica necessariamente em divergências com os processos de participação considerados essenciais ao museu, pois é possível, mesmo no âmbito formal, a construção participativa no âmbito da coletividade dos sujeitos envolvidos, ou mesmo, a partir de sistemas de representação, quando assim for a opção do grupo. Contudo, apesar de não ferir este elemento estruturante, a formalização pode intervir em um outro elemento - a identidade territorial. Deslocando o olhar para grupos indígenas, por exemplo, depara-se com comunidades que têm este elemento desconsiderado pela sociedade não indígena, de modo geral. Processos institucionalizados, nestes casos, podem incorrer no risco de subjugar estes grupos aos mecanismos burocráticos formais do Estado e da sociedade de direito, fugindo à própria dinâmica cultural local, em um processo que, dificilmente, será sustentado por integrantes do grupo em si.

Em suma, o processo de formalização organizacional é possível, mas a atenção deve ser voltada para a análise de viabilidade em cada caso, pois se a formalização se tornar um impositivo ao grupo, desconsiderando a sua realidade cotidiana e a sua dinâmica sociocultural, poderá acarretar na desmobilização do grupo na causa do museu ou na própria descaracterização do que seria o elo identitário, caindo em uma grande incoerência funcional.

\subsection{Gerenciando o Museu com base na Participação Comunitária e na Identidade Territorial}

Para compreensão das propostas de gerenciamento abordadas a seguir, é necessário retomar duas premissas 
indicadas na caracterização da mobilização organizacional. Primeiro, parte-se da adoção da forma processual-relacional para caracterizar as atividades gerenciais do museu, em contraponto à forma sistêmico-controladora. A primeira consiste na compreensão da organização com fenômeno relacional e dos indivíduos, seus membros, como seres relacionais, logo, tudo está inserido nos processos contínuos e interdependentes das relações sociais, econômicas, políticas e culturais das quais fazem parte. Já a segunda forma, descartada neste trabalho, refere-se a um mecanicismo do trabalho gerencial, em que as organizações são vistas como grandes sistemas controláveis e orientadas para resultados, com metas organizacionais objetivas, deixando de lado os aspectos subjetivos referentes àquilo que esta sendo "gerenciado" e por quem (Watson, 2005). A vocação prática, com orientações e propostas pragmáticas, pode parecer, em alguns momentos, normativa e prescritiva. Todavia, as orientações e princípios devem ser entendidos, neste texto, como âncoras reflexivas para facilitar e aprimorar a prática. Se alguns princípios são elegidos como fundamentais (por exemplo, a participação comunitária e a identidade territorial), as ações e decisões devem ser coerentes com esses princípios. Nem tudo pode ser feito de qualquer forma. O que pode parecer normatividade e prescrição, deve ser entendido como coerência e aderência ética para com esses princípios.

$\mathrm{Na}$ perspectiva da mobilização organizacional, toma-se a gestão como uma das variáveis organizacionais, porém, como dito anteriormente, com papel central, por sua função articuladora das "diferentes dimensões" ou "variáveis constitutivas" (França Filho, 2004). A organização, citada como fenômeno relacional, implica as várias dimensões de relações possíveis com o território para a sua própria caracterização. Logo, a gestão jamais pode ser descolada desta realidade, bem como não haverá modelo perfeito de gestão aplicável a qualquer situação. "A criação de modelos de gestão provém da realidade 
concreta dos seres humanos envolvidos em situações de associação que requerem respostas sobre sua organização, participação e mesmo sobre seus valores e objetivos" (Ma, 2014, p.10).

Dito isso, a proposta de gerenciamento estrutural de um museu comunitário, não será diferente. Assim, a identidade territorial que este museu conforma no decorrer dos seus processos, é levada em consideração para a operacionalização das ações mais cotidianas num ambiente organizacional, como a gestão de equipes/pessoas, de espaços e recursos. De igual modo, os processos participativos também estão ligados ao desenvolvimento destas atividades, ainda que alguns grupos deliberem pela responsabilização de determinado membro para uma ou outra atividade. O que está em jogo é a atuação destas figuras, que de algum modo, exercem lideranças, mesmo em organizações autogestionadas. Ressalta-se o entendimento da liderança não como sinônimo de gestão, ou seja, líderes não são necessariamente gestores. Nesse sentido, em organizações autogestionadas, podem existir pessoas mais influentes, em alguns momentos, pois se identificam mais com determinados processos ou assuntos. Então, a liderança pode ser momentânea e ligada a um assunto específico. Nesse sentido, entende-se que não há contradição entre expressão da liderança e autogestão.

Sob a ótica processual-relacional, as figuras de gestão em um museu comunitário serão destacadas como "aprendizes competentes", que desenvolvem, "em interação com os outros, habilidades humanas, sociais, culturais, políticas e econômicas primordiais (...) se envolvem em processos de construção social da realidade, em vez de tentarem 'criar' culturas organizacionais" (Watson, 2005, p. 22). Cabe as estas figuras, o papel de mediar processos de trocas, negociações, conflitos e compromissos, como atividades gerenciais, uma vez que as organizações devem ser orientadas estrategicamente, num esforço de permanência, a partir de uma "relativa estabilidade" e de um "relativo estado de 
organização", pois compreende que tudo está em transformação constante.

Com efeito, "a gestão como prática administrativa" tem a "organização como lócus privilegiado da/e para uma ação administrativa personalizada" (Ma, 2014, p.11). Sendo a organização um museu comunitário, a prática administrativa proposta é baseada na cooperação entre indivíduos, membros da comunidade do museu, considerando a participação e a identidade territorial para o gerenciamento coletivo de equipes, espaços e recursos, financeiros ou não.

\subsubsection{Gerenciando Coletivamente uma Equipe}

Outra estratégia importante na mobilização organizacional, e que possui relação com a própria ideia de sustentabilidade do museu, é o formato da gestão da equipe de trabalho. Os relatos dos gestores e líderes dessas organizações apresentam um perigo constante para a gestão que é a indefinição de papéis e responsabilidades concretas, seja pela existência frequente de líderes centralizadores, seja pela omissão e fuga das responsabilidades por grande parte dos integrantes. Isso pode acarretar tanto num número grande de pessoas participantes das ações, encontros e reuniões, mas poucos responsáveis pela execução de tarefas e funções, ainda que tenham sido pensadas coletivamente; quanto em um esvaziamento de pessoas em prol do museu, quando estas não enxergam em que efetivamente podem contribuir.

Além disso, é necessária a atenção para os mecanismos de operacionalização desta equipe em formação. É muito comum surgir personalidades fortes, mais expressivas em suas falas, que aos poucos assumem um lugar social de destaque dentro museu, ainda que simbolicamente, figuram-se como líderes. Geralmente, essas pessoas tem consciência do poder que exercem, e cientes disso, podem utilizar de forma prejudicial, manipulando o grupo, e inibindo as particularidades de formas de expressão de outros indivíduos, como podem utilizar de forma mediadora e 
estimuladora do diálogo e da construção coletiva. Na prática, este discernimento é muito difícil, pois se trata de situações profundamente subjetivas, que somente à luz de outras ciências e campos do conhecimento podem ser melhor analisada. Seria o caso da psicologia social e ambiental aplicadas ao campo organizacional (Clegg et al., 2011; Kets de Vries, 2010; Farias \& Pinheiro, 2013). De todo modo, cabe o cuidado e atenção do grupo com as dissonâncias existentes entre teoria e prática, discurso e ação. Essas dissonâncias são destacadas pelas pessoas de outros museus comunitários como um dos principais fatores desmobilizadores.

É importante valorizar as vocações e interesses individuais de cada pessoa envolvida do grupo nos encontros destinados ao gerenciamento das atividades do museu, potencializando a sua ação a partir das expertises emergentes dos próprios atores do grupo, delineando, neste âmbito coletivo, as responsabilidades e estruturando equipes de trabalho. Consequentemente, o grupo deve definir uma periodicidade destes encontros de gestão das ações, de modo que, conjuntamente, possam acompanhar, avaliar e promover o desenvolvimento do museu. Nestes encontros, identifica-se se há flutuações na equipe, a exemplo de pessoas que participaram, assumiram responsabilidades, porém não estão mais integrando a equipe por algum motivo, bem como a existência de pessoas novas, que estão chegando e se aproximando do processo do museu dispostas a construir conjuntamente. Previamente, indica-se ter em vista o planejamento museológico do museu, norteador das ações e da própria estruturação da iniciativa, de modo que a formação de equipes possa ser visualizada em consonância com as demandas previstas, não impedindo a adequação do plano, se necessário.

Dessa forma, o gerenciamento coletivo de equipes é uma ação constante, não restrita a uma pessoa, e que contará sempre com esta fluidez própria da dinâmica participativa comunitária do museu. Porém, como apontado, não é aleatória, ou segue de 
forma impensada, tendo em vista tanto os riscos apresentados, como a própria dificuldade de engajamento e esvaziamento da organização. Trata-se, antes de tudo, de uma estratégia de ação, logo, precisa ser refletida, avaliando os elementos territoriais e as estruturas organizacionais próprias de cada contexto, buscando o alinhamento e a sinergia destes fatores, para a devida operacionalização desta ação.

\subsubsection{Gerenciando Espaço Físico}

Muitas iniciativas museológicas comunitárias não, necessariamente, possuem um espaço físico institucional. Entretanto, as ações do museu no território não ocorrem soltas no ar, ainda que não sejam restritas, meramente, a sua dimensão física. Dessa forma, esta estratégia refere-se ao gerenciamento dos espaços físicos que o museu utiliza em determinado território.

Um exemplo é o Movimento Ecomuseu de Sepetiba, no Rio de Janeiro (experiência relatada por Bianca Wild e Bruno Cruz de Almeida, articuladores do movimento Ecomuseu de Sepetiba; http://www.abremc.com.br/artigos3.asp?id=4. Acesso: 29 de outubro de 2016). Considerado como uma iniciativa comunitária por parte de uma diversidade de agentes locais do território, o museu desenvolve as funções básicas museológicas através de ações de preservação, pesquisa e comunicação de diversos patrimônios culturais materiais e imateriais, sendo os de natureza material a céu aberto. A dimensão desse patrimônio ultrapassa a gerência única do museu, envolvendo o poder público municipal, quando não, também, o estadual e federal, devido à legislação do país. É necessário que este espaço conste no Plano Museológico do referido museu como espaço também da sua responsabilidade, evidenciando a sua limitação, mas também a sua potencialidade de gerência sobre ele. Em casos como este, indica-se a busca da gestão compartilhada desse bem com demais atores no território, cabendo ao museu o papel de 
articulador desta ação, configurando esta, por exemplo, como sua parcela de responsabilidade pelo referido espaço que, ao mesmo tempo, é meio (espaço de desenvolvimento de ações socioculturais e educativa) e produto (como patrimônio em si) da ação museológica.

Podemos considerar iniciativas museológicas que predispõem de espaços físicos próprios, abrigando (como de costume) acervos e coleções próprias referentes à identidade territorial assumida. Nestes casos, o gerenciamento destes espaços baseia-se nos princípios da participação e da identidade e pode se beneficiar de duas práticas: (a) a gestão do uso e (b) a gestão de manutenção.

Sobre a gestão de uso, é importante ressaltar a existência de políticas de uso dos espaços museológicos que estimulem a polivalência de seus usos, entendendo que esta é uma característica estratégica para o acolhimento das demandas comunitárias, assim como para a dinamização do museu. Mais que isso, deve-se ter em vista a "utilidade do museu para o desenvolvimento das pessoas e do território, sendo por isso essencial que, a cada passo, a comunidade seja parte ativa do processo museológico" (Sancho-Querol \& Sancho, 2014, p. 22).

Um museu comunitário está sempre atento às necessidades sociais da população que o cerca, buscando ser útil a esta. Restringir-se a um mostruário de peças apenas, sem uma reflexão crítica que contribua para o presente, seria, portanto, uma incoerência diante dos compromissos sociais deste museu. Para tanto, a escuta ativa da comunidade é fundamental, em todos os processos museológicos, seja em encontros de planejamento coletivos, de avaliação da atuação do museu junto à comunidade, ou outras situações possíveis. O importante é promover espaços concretos de participação, de fala e de escuta (Moura \& Gianellla, 2016), necessários para esta construção coletiva. 
A gestão da manutenção envolve diretamente a gestão de recursos (financeiros ou não) para o tratamento devido dos espaços físicos, desde a manutenção mais cotidiana, ligada a ações de higienização básica, à necessidade de reformas e restaurações de estruturas. Logo, nestes casos, a equipe do museu levanta as possibilidades que tem, seja de recursos financeiros diretos para manutenção de trabalhadores direcionados para estes serviços, bem como, dos materiais necessários; seja de outros recursos, frutos de parcerias, trocas, voluntariado, doações que possa satisfazer as necessidades do museu.

Cabe uma avaliação organizacional para perceber quais necessidades não podem depender continuamente de recursos a captar, como por exemplo, a manutenção básica do museu, que envolve sua higienização e os materiais necessários para isso. Certas demandas exigem uma gestão que lhes proporcionem um grau de perenidade, caso contrário, as pessoas ao redor do museu não terão como efetivamente desempenhar suas 'ações fins', pois estarão cotidianamente preocupadas em satisfazer apenas as 'ações meio', protelando o objetivo final da iniciativa. Em outros casos, como em demandas pontuais (obras específicas, projetos de restauração e/ou reforma, etc.), as atividades "meio" podem convergir para a ação fim, de forma que o desenvolvimento de parcerias como alternativa para a execução de algumas destas demandas pode contribuir também para outras atividades do museu, relacionadas, por exemplo, às ações de preservação do patrimônio no território de forma compartilhada.

\subsubsection{Gerenciando Recursos e Finanças}

Esta estratégia prevê a gestão de recursos e finanças, tendo em vista o gerenciamento da dimensão física e simbólica do museu, prezando por sua sustentabilidade organizacional. A partir das discussões sobre desenvolvimento sustentável (Dessein 
et al., 2015; Rattner, 1999; Diegues, 1992), a sustentabilidade organizacional procurou ampliar os seus horizontes para além dos aspectos financeiros, sendo definida por Santos (2005, p.136) como a "capacidade de sobrevivência da organização, através do tempo, garantida pela inter-relação de diferentes dimensões que, associadas, possibilitam a execução da missão organizacional e o enraizamento dos seus princípios e valores na sociedade". Dentre essas dimensões, pode-se listar a dimensão técnica, política e econômica (Santos, 2005; Perônico, 2004 apud Tude et al., 2009).

Entretanto, nesta estratégia, o foco será para a dimensão econômica, referindo-se à gestão de recursos necessários para o desenvolvimento da inciativa museológica comunitária, tendo em vista que, outras estratégias contribuem para as demais dimensões. Faz-se necessário, contudo, esclarecer que a dimensão econômica não se refere apenas aos elementos financeiros, relacionados ao princípio mercantil da economia e suas relações de, para e com o mercado. A captação e o gerenciamento de recursos referem-se a todos os tipos de recursos necessários para o funcionamento da iniciativa, sejam eles monetários ou não.

Logo, uma ação é propícia: um encontro da comunidade para reflexão sobre quais são as demandas da comunidade para o museu, e o que este precisa para desenvolver sua função social, tendo em vista a sua missão. Deste levantamento, alimenta-se a reflexão sobre quais recursos são necessários para realizar as ações e operacionalizar todas as demandas do museu. A partir deste encontro, é possível realizar três objetivos: (a) identificar as necessidades sociais comunitárias demandadas ao museu, com intuito de refletir sobre as possibilidades de atividades econômicas que a própria demanda comunitária gera; (b) identificar os recursos necessários para o desenvolvimento, pelo menos, das atividades básicas iniciais; e (c) visualizar quais as necessidades de recursos financeiros diretos e quais recursos podem ser alcançados por outros caminhos - parcerias, trocas, 
voluntariado, campanhas de doação, contribuições de amigos do museu, entre outras.

Dentre estes objetivos, destaca-se a importância do levantamento das demandas comunitárias direcionadas ao museu. Ou seja, o que a comunidade espera de nós? O que a comunidade espera encontrar neste espaço? Quais serviços são vislumbrados? Quais são as necessidades e de que forma o museu pode colaborar para a contemplação destes anseios? 0 que a comunidade pode oferecer?

Esta ação oferecerá suporte para a criação futura de um plano de desenvolvimento econômico do museu, centrado nas possibilidades de ações a serem desenvolvidas pelo museu ou por meio dele, a partir da identificação das potencialidades imediatas da comunidade. O intuito é que o museu seja um elemento mobilizador da economia local, através da geração de trabalho direto ou indireto. Um equipamento cultural planejado em consonância com o seu território pode promover o turismo sustentável, a possibilidade de novos comércios e serviços locais. Nesta perspectiva, o museu, a partir da memória e do patrimônio que salvaguarda, é percebido claramente como um fator potencial de desenvolvimento local, inserindo-se na lógica econômica local (Varine-Bohan, 2013), conferindo ganhos à comunidade, numa perspectiva de desenvolvimento mais humana e solidária.

Entretanto, para concretização deste plano, é necessário realizar encontros formativos da comunidade do museu para capacitação com vistas à construção de um plano de desenvolvimento econômico territorial. A presença da mediação de profissional qualificado na área será importante. Busca-se envolver o poder público local, assim como outras organizações do território, sobretudo, ligadas diretamente ao museu, para a construção participativa de um plano de desenvolvimento econômico fincado em modelos integrados, sustentáveis e equitativos. 
Seguindo, para melhor compreensão das possibilidades de captação de recursos de uma organização, é preciso, primeiramente, compreender de qual modelo e estrutura organizacional está se tratando. Isso porque, um museu comunitário vinculado ao poder público implicará em lógicas de funcionamento e de captação de recursos diferenciadas de uma iniciativa não formal caracterizada por algum coletivo local.

Sendo assim, propõem-se encontros formativos para capacitação da equipe do museu para desenvolvimento de um plano de mobilização de recursos, a partir dos conhecimentos sobre as diversas formas de financiamento e captação de recursos aplicáveis ao museu, a depender da sua natureza, seja público, privado ou constituído como organização da sociedade civil formal ou informal. Mediado por profissional capacitado. Sugere-se a discussão sobre a sustentabilidade organizacional pretendida pelo grupo, tendo em vista o modelo de gestão adotado, e, considerando a sua condição comunitária e a sua identidade territorial, como fatores de relevância.

Entretanto, independente da natureza organizacional do museu, ou mesmo se este já possui orçamento fixo, sugere-se a constituição de um setor (uma comissão, um grupo ou uma pessoa) direcionado exclusivamente para formas de captação e financiamento, atentando-se para as possibilidade de editais públicos e privados, mecanismos de resdistribuição de renda através de aportes do estado, estratégias de financiamento coletivo ou geração de recursos próprios.

Sobre a captação e a própria geração de recursos é necessário romper com a ideia de uma sustentabilidade do museu, a partir da sua própria capacidade de geração de recursos. Isso pode acarretar no comprometimento das atividades fins do museu, impactando negativamente em seus objetivos organizacionais. Além disso, deve-se problematizar a ideia de sustentabilidade unicamente atrelada a auto suficiência finanecira do museu. Consequentemente, torna-se também 
estratégico discernir quais parcerias e investidores converge com a missão do museu e quais divergem, ou pior, chegam a provocar a ineficiência do trabalho do museu comunitário, por possuir objetivos opostos e excludentes. A partir deste discernimento, toma-se a decisão política, uma vez que, cada iniciativa deve ter a liberdade de definir de que modo lidar com estas divergências, a partir da escuta ativa à diversidade de pontos de vista na comunidade, para desenvolver uma postura crítica reflexiva e consciente da atuação do museu e da sua identidade organizacional.

\section{A Mobilização Museológica Interorganizacional}

Essa mobilização refere-se a estratégias de articulação do museu comunitário com outras instâncias organizativas, entendendo a necessidade destes laços para a sua sustentabilidade. Estes vínculos podem ser perenes ou pontuais, assim como podem ser construídos com uma ou mais organizações. O objetivo maior, entretanto, é a criação de uma rede de cooperação interorganizacional no território a partir da articulação do museu, bem como a sua inserção em redes préexistentes.

Por interorganizações pode-se compreender um "tecido híbrido formado por organizações que atuam em conjunto" (Fischer \& Melo, 2004, p.18), conectadas e integradas por propósitos comuns. Trata-se de organizações complexas, que se constituem pela busca da cooperação entre diferentes atores sociais para atingir um mesmo resultado. "São espaços multiformes e plurais onde ocorre a gestão da sociedade contemporânea que ultrapassa os limites de uma organização e se exercem em escalas de complexidade crescente com conexões e interdependências" (Fischer, 2012, p.114).

O manejo das identidades culturais, atividade familiar aos museus, se renova. A formação da interorganização pressupõe um processo continuado de negociação das múltiplas identidades 
em interação num determinado território, construído unicamente na dinâmica estabelecida por estas relações, dando formato a uma identidade territorial comum. Dessa forma, as interorganizações expressam os interesses plurais das organizações que operam em um espaço cujo contorno é definido por este próprio grupo.

Ao conjunto formado por estas organizações, propõe-se a constituição de uma rede de cooperação interorganizacional, tendo em vista a temporalidade que permeia essas relações. Pode-se falar de uma rede com data de início e término, como se pode constituir uma rede pontual para determinada ação, ou ainda, uma rede perene, com ambições de sustentabilidade no decorrer dos anos. A gestão da sociedade contemporânea da qual se fala, então, refere-se à gestão de redes. A ideia de rede, por sua vez, é compreendida como a união de pessoas em torno de um objetivo comum, compartilhando valores e princípios, a partir de processos descentralizados de multilideranças e autonomia (Martinho, 2001). Assim, a própria organização do museu comunitário também pode ser entendida como uma rede de atores sociais que tem em comum, inicialmente, a "vontade de museu" (Chagas, 2007).

As relações de vizinhança estabelecidas pelos museus e seus pares, potencializadas também por aspectos da identidade territorial assumida politicamente pelos grupos, dão lugar a estas novas formas de organizações, mais independentes e autônomas em relação às questões do seu território, apesar de interligadas entre si. Assim, as organizações e interorganizações com diferentes graus de imbricamento contribuem para uma nova forma de visualizar o desenvolvimento territorial (Fischer \& Melo, 2004).

A rede de cooperação inteorganizacional tem em vista a relevância estratégica dos processos comunitários para a dinamização sociocultural de territórios, possibilitando a inserção de comunidades na economia criativa local, nacional e 
internacional, bem como, o desenvolvimento sócioterritorial sustentável, ou melhor, a construção de sociedades sustentáveis (Diegues, 1992; Rattner, 1999, Dessein et al., 2015), baseadas num modelo de desenvolvimento integrado, equitativo e solidário.

A mobilização museológica interorganizacional refere-se às estratégias de gestão focadas na articulação como atividade base do museu, seja este configurado por natureza como uma interorganização, seja este posto em interação com outras instâncias organizativas, necessárias para a sua sustentabilidade. O objetivo maior é a criação de uma rede de cooperação interorganizacional no território a partir da articulação do museu e/ou a sua inserção em redes pré-existentes. Para tanto, ressaltase a importância de articulação com outras organizações, públicas, privadas, não governamentais e populares.

Além de servir para o fortalecimento das iniciativas museológicas comunitárias, a Mobilização Museológica Interorganizacional reforça o papel crucial que estas organizações desempenham em suas comunidades, compreendendo que através delas, outros projetos e propostas comunitárias podem ser impulsionadas, a partir da visão do patrimônio e da memória como capital sociocultural de um grupo, e para o desenvolvimento de uma consciência coletiva que é fundamental para o desenvolvimento de ações com alto nível de transformação social.

\subsection{Gerenciando a Relação com Organizações Não Governamentais e Populares}

Essa estratégia prevê a articulação do museu comunitário com organizações não governamentais e populares, por meio da realização de encontros pra diálogo sobre a missão e os projetos das organizações envolvidas. Essa articulação pode aproximar o museu dos movimentos populares e sociais, fortalecendo-os e compondo-os, abrindo um canal de troca e aprendizado mútuo. 
Leva-se em consideração também que existe uma grande variedade de organizações cujas missões estão relacionadas com os esforços das comunidades por conhecer e proteger sua própria cultura (Lersch \& Ocampo, 2009). Dessa forma, tem em vista a potencialização de demandas e ações comuns, ou seja, a luta contra o atomismo/individualismo dos movimentos e o enfraquecimento da mobilização social no território ou da sociedade civil organizada.

Provocar ou se abrir para o diálogo com organizações não governamentais e populares, além de fortalecer a mobilização social de territórios, enseja também dinâmicas sociais que colaboram para melhores condições de vida. Isto acontece, de um lado, pelo nível de organização da sociedade civil para apresentação de demandas ao poder público e privado. Por outro lado, isso acontece pela própria articulação e desenvolvimento de ações socioculturais e educativas de forma coletiva no próprio âmbito da sociedade civil. Essas ações envolvem a conscientização social da comunidade de sua responsabilidade pela melhoria da qualidade de vida, pela promoção da igualdade e dos direitos básicos e pela própria preservação do patrimônio, para além das ações do Estado, até então, tido como seu único guardião.

Essas relações, a médio e longo prazo, contribuem para o exercício da participação cidadã nos diversos âmbitos sociais, colaborando para a construção de relações de sociabilidades com base no respeito e na tolerância à diversidade sociocultural existente. Aos poucos, o indivíduo é inserido na trama social, de forma engajada, exercendo a cidadania até então adormecida.

Dentre as relações com organizações não governamentais e populares, destacam-se alguns potenciais parceiros para a articulação com o museu comunitário, a saber:

- Iniciativas de Redes de Museus pelo país. Boa parte dos estados brasileiros possui pelo menos uma rede de museus, independentes de sua especificidade. São Redes 
de Educadores em Museus, Redes de Memória e Museologia Social, Redes de Museus Indígenas e Museologia Social, entre outras.

- Associação de Amigos do Museu ou Associações Comunitárias de Bairro. Vale destacar que, atualmente, as Associações de Amigos do Museu têm sido utilizadas como instrumentos de captação de recursos e gerenciamento dos museus.

- Movimentos Sociais abrangentes. É válida a inserção do museu em movimentos sociais que condizem com a sua missão. Sendo também um espaço de poder e de luta, considera-se importante a afirmação de uma postura do museu comunitário, posicionando-se diante dos maiores dilemas sociopolíticos.

\subsection{Gerenciando a Relação com Organizações Públicas: Municipais, Estaduais e Federais}

Esta outra estratégia prevê a realização de encontros para diálogo sobre a missão e os projetos do museu com instituições públicas, da esfera municipal, estadual e federal do território. Essa articulação é fundamental para colocar o museu comunitário no rol dos interesses públicos, uma vez que o próprio surgimento do museu está intimamente atrelado a interesses e preocupações profundas de determinada comunidade.

Ainda que não tenha vínculo formal com nenhum nível do poder público, espera-se que a demanda da organização comunitária do museu seja não só apresentada à esfera pública, mas que se torne pauta de diálogo e luta dessa comunidade. Essa inter-relação é inerente à tipologia deste museu, pois a base da preservação que o museu comunitário sustenta se dá justamente através da gestão comunitária do patrimônio, da realização de ações socioculturais e educativas que possibilitam um novo olhar do indivíduo para o seu espaço e da sociedade para o seu território, mediado pelos seus referenciais de patrimônio. Esse 
novo olhar, por sua vez, está relacionado à formação cidadã do sujeito, que se coloca como agente ativo em prol do desenvolvimento social da sua comunidade (Varine-Bohan, 2013; Priosti, 2007).

É fundamental que a iniciativa museológica comunitária se coloque como um ator social presente na construção de políticas públicas para a cultura, favorecendo o diálogo através da permeabilidade que deve cultivar em seu território, por meio da construção coletiva aberta ao acolhimento de múltiplas identidades e do desenvolvimento de espaços propícios à participação. Lista-se, abaixo, as principais instituições públicas necessárias ao cotidiano de um museu comunitário:

- Esfera Municipal - a Secretaria de Educação e Cultura do(s) município(s) que o museu integra, assim como o Conselho de Cultura e/ou de Patrimônio do Município (se houver).

- Esfera Estadual - os órgãos vinculados à Secretaria de Cultura do Estado que lidam com museus, patrimônio e a memória. Por exemplo, na Bahia, seria o Instituto do Patrimônio Artístico e Cultural da Bahia, através da sua Diretoria de Museus. Além disso, alguns estados apresentam dentro do organograma do poder público, os Sistemas de Museus Estaduais, que podem ser parceiros importantes a depender da ação.

- Esfera Federal - o Instituto Brasileiro de Museus, que possui interface também com o Sistema Brasileiro de Museus. Além disso, pode-se listar a maior parte dos cursos de Museologia pelo país, que seja de graduação ou pós-graduação, vinculam-se a instituições públicas federais.

\subsection{Gerenciando a Relação com Organizações Privadas}

A realização de encontros para diálogo sobre a missão e os projetos do museu com instituições privadas trata-se de mais 
uma estratégia para a articulação do museu com outra gama de organizações. Essa articulação talvez seja um dos principais braços de captação de recursos para o museu, pois empresas se aproximam como um investidor direto, vislumbrando possibilidades de retorno financeiro ou prestígio social, quando não por obrigação legal, em alguma instância do museu.

Entretanto, não se pode reduzir o interesse da empresa com base numa relação monetizada com o museu. Afinal, as empresas também são formadas por pessoas que estão imersas em realidades socioculturais diversas e imbricadas em valores e princípios próprios. Logo, pode-se concretizar relações das mais diversas, não necessariamente balizadas diretamente pelo fator financeiro, mas por outras relações com o território. Um exemplo seria o desenvolvimento de um museu comunitário em determinado território que viesse colaborar para a pavimentação de ruas, infraestrutura urbana e movimentação social, impactando a realidade local, favorecendo a sociedade de modo mais amplo. Este é um caso, em que o museu torna-se mais um ator social do território, porém diante das suas possibilidades, pode ser potencializado por relações de vizinhanças tendo em vista o ganho social maior por trás da ação da comunidade através do museu.

A atividade de uma iniciativa museológica comunitária gera uma teia de relações sobre o território, inclusive relações econômicas, surgimento de novos empreendimentos e comércios locais. Daí a importância desta movimentação se dar de forma articulada com os setores da própria região, pois possibilita o planejamento coletivo e a preparação de uma estrutura ao redor da ação do museu, de forma que este potencializa estas relações, mas também é potencializado e ganha visibilidade graças a elas.

Dois pontos, contudo, demandam maior atenção na articulação com empresas, sobretudo, de grande porte. Primeiro, a possibilidade do grupo local, mobilizador do museu comunitário, discernir quais investidores convergem com a 
missão do museu e quais divergem diretamente, e até colaboram, no dia-a-dia de operação da empresa para a ineficiência do trabalho do museu comunitário, por possuir objetivos opostos e excludentes. A partir deste discernimento, espera-se a tomada de decisão política por parte do museu, delineando os moldes da sua atuação em conjunto com estas organizações, uma vez que, cada iniciativa deve ter a liberdade de definir de que modo lidar com estas divergências. De todo modo, orienta-se para o estabelecimento de parcerias com instituições privadas que não venham a ferir diretamente a ética do museu e o que este estabelece como seu propósito.

O segundo ponto de atenção refere-se à consciência da comunidade em relação ao envolvimento das empresas, sobretudo, as de grande porte, que ultrapassem a obrigação legal de responsabilidade social. Por mais que existam empresas com linhas de investimento social, esta nunca será a finalidade principal da empresa, de modo que, num momento de crise ou até mesmo de redefinição dos seus pilares, este se torna um dos pontos mais fracos e com riscos de corte iminente. Dessa forma, o museu comunitário não reduz seus horizontes de captação a este tipo de relação apenas.

Destaca-se, por fim, as iniciativas privadas por localização referente ao seu potencial de vinculação:

- Empresas Locais - além de possíveis financiadores diretos do museu, as pequenas e médias empresas locais podem se relacionar com o museu de forma mais imbricada, seja como um possível ator social comunitário que integra a base do museu, pelo interesse despertado nas pessoas proprietárias destes estabelecimentos, seja numa ação interorganizacional sobre o território comum, tendo em vista a possibilidade de retorno pra ambos.

- Empresas Regionais e Nacionais - tendem a se relacionar com os museus, na perspectiva da obrigação legal de condicionantes sociais para consecução dos seus fins, 
porém, também se interessam por impactos sobre o seu território de abrangência, podendo configurar um parceiro em potencial.

- Empresas Multi e Transnacionais - raramente estabelecerão relações informais com o museu, de forma que, o acesso a estas empresas se dá através de mecanismos formais de fomento ou de parcerias, convênios e termos de cooperação. Dessa forma, a articulação com estas empresas exigem, geralmente, projetos, um alto nível de exequibilidade financeira e comprovação do potencial de ação do museu.

\section{Discussão e Conclusões}

Sem desconsiderar as possibilidades do definhamento de iniciativas museológicas comunitárias por questões relacionadas à própria ausência do estímulo propulsor destas iniciativas, configurado pelo que se pode entender pela "vontade de museu", "vontade de memória" e "vontade de patrimônio" (Chagas, 2007), destaca-se neste artigo as possibilidades de atuação no campo da gestão, entendendo que este pode ser um fator de maior sobrepeso ao analisar a conjuntura destas inciativas. Entretanto, deficiências de gestão raramente são apontadas como causas para este tipo de situação. Porém, diante da escassez de estudos sistematizados sobre as práticas de gestão de iniciativas museológicas comunitárias, faz-se urgente o desenvolvimento destas (e outras) estratégias de gestão (Quadro 1), sintonizadas com a própria natureza destas iniciativas e com a sua dinâmica cultural local.

Com as estratégias de gestão propostas, pretende-se contribuir com o desenvolvimento de iniciativas museológicas comunitárias, tendo em vista o papel central da participação comunitária e da identidade territorial para os seus processos de gestão. Além disso, a compreensão global do museu enquanto processo interligado, a partir das estratégias propostas, colabora para equalizar um dos maiores desafios de gestão de 
equipamentos culturais como um todo, relacionados à constante dissociação entre áreas fins e áreas meio. Nesse sentido, a principal contribuição desse artigo é prática, voltada para capacitar a prática profissional e ativista em comunidades por meio de um conjunto de propostas que não são receitas a serem seguidas, mas propostas reflexivas com vocação praxeológica. Por outro lado, como o campo de estudos sobre gestão de museus e em específico sobre gestão de museus

Quadro 1 - Estratégias de Gestão

\begin{tabular}{|c|c|}
\hline Foco da estratégia & Ações da estratégia \\
\hline \multicolumn{2}{|c|}{ Mobilização Museológica Organizacional } \\
\hline \multirow[t]{2}{*}{$\begin{array}{l}\text { Construção da identidade } \\
\text { organizacional }\end{array}$} & $\begin{array}{l}\text { Realizando o diagnóstico } \\
\text { participativo do museu }\end{array}$ \\
\hline & $\begin{array}{lllll}\begin{array}{l}\text { Estabelecendo } \\
\text { organizacional }\end{array} & & \text { modelo } & \text { a estrutura } \\
\end{array}$ \\
\hline \multirow[t]{3}{*}{ Gerenciamento o museu } & Gerenciando coletivamente uma eEquipe \\
\hline & Gerenciando espaço físico \\
\hline & Gerenciando recursos e finanças \\
\hline \multicolumn{2}{|c|}{ Mobilização Museológica Interorganizacional } \\
\hline \multirow[t]{3}{*}{$\begin{array}{l}\text { Gerenciamento da } \\
\text { relação com organizações }\end{array}$} & $\begin{array}{l}\text { Mobilizando organização não governamentais e } \\
\text { populares }\end{array}$ \\
\hline & $\begin{array}{l}\text { Mobilizando organização públicas: municipais, } \\
\text { estaduais e federais }\end{array}$ \\
\hline & $\begin{array}{l}\text { Mobilizando organização privadas: locais, } \\
\text { regionais, nacional, multinacionais e } \\
\text { transnacionais }\end{array}$ \\
\hline
\end{tabular}

comunitários ainda está em construção, carecendo de uma consolidação de conhecimentos, entendemos que esse artigo também pode contribuir para ampliar e enriquecer o campo de pesquisas sobre gestão de museus comunitários.

Um projeto de gestão organizacional "unifica de modo a operar com eficiência, as atividades meio com as atividades fins" (Cury, 2010, p. 274). A mobilização organizacional promove esta visão holística do museu, integrando essas áreas a partir da adoção de práticas participativas para operacionalização das atividades suporte às ações museológicas finais. A própria 
mobilização museológica interorganizacional contribui para esta visão complexa da organização e das suas potencialidades de articulação e integração com outros atores sociais de um mesmo território.

Com o desenvolvimento deste trabalho, ao reforçar a ideia do "museu processo", enfatizando sua importância para modelos de desenvolvimento mais integrados, equitativos e solidários, nota-se que estes processos não são dados num território. Um museu comunitário não nasce e morre, aleatoriamente. Exige esforços para nascer, assim como existe as causas de morte. 0 museu, por ser processo, não está perdido em movimentos aleatórios, unicamente dependentes do rumo seguido pela dinâmica cultural local, sem interferência de agentes que pensem e que ajam sobre este processo, conferindo um certo ritmo a essa dinâmica natural. Esse artigo forneceu elementos para avançar nessa reflexão e nessa concepção processual da gestão museológica, dentro dos princípios de participação comunitária e de identidade territorial, mas também propondo as categorias de mobilizacão como fecundas para se pensar a gestão. Além disso, ajuda a visualizar a gestão como atividade não somente interna, mas também como relação com outras organizações, de tipos distintos e diversos.

Mesmo uma organização sob a análise processualrelacional descrita por Watson (2005), requer uma certa ordem e esforços gerenciais e organizacionais. A diferença consiste na forma de construção desta ordem, que, diferentemente dos sistemas top down, impositivos e hierárquicos, vem de um movimento de base, bottom up, que requer negociação e mediação de conflitos. Em oposição a simples aplicação de técnicas e métodos da museologia "tradicional", oriundos da administração clássica, estas iniciativas exigem da gestão um exercício de mediação.

Este trabalho é uma sistematização de estratégias possíveis diante de um cenário que é muito mais amplo. Por isso, 
pode também ser entendido como uma provocação para a necessidade de mais pesquisas e estratégias. Necessitamos de contribuições práticas e teóricas para que a gestão de museus comunitários aconteça efetivamente, não só na teoria, mas também na prática cotidiana de nossas sociedades contemporâneas.

\section{Referências}

Arnstein, S. R. (2002, janeiro). Uma escada da participação cidadã. Revista da Associação Brasileira para o Fortalecimento da Participação - PARTICIPE. Porto Alegre/Santa Cruz do Sul, 2(2), 4-13.

Bordenave, J. (1983). O que é Participação? São Paulo: Editora Brasiliense. Boylan, P. (org.) (2004) .Como gerir um museu: Manual Prático. Paris: ICOM. Brasil. Lei Federal no 11.904 de 14 de janeiro de 2009. Estabelece o Estatuto de Museus e dá outras providências. Disponível em: < http://www.planalto.gov.br/ccivil_03/_Ato2007-2010/2009/Lei/L11904.htm>. Acesso em 5 março 2016.

Canclini, N. G. (2003). Culturas Híbridas: estratégias para entrar e sair da modernidade. São Paulo: Eadusp.

Cândido, M. M. D. (2013) Gestão de Museus, um desafio contemporâneo: diagnóstico museológico e planejamento. Porto Alegre: Medianiz.

Cândido, M. M. D. (2014). Orientações para Gestão e Planejamento de Museus. Florianópolis: FCC.

Cezário, H. B. M.; Davel, E.; Sancho-Querol, L. (2017). Tecnologia Social das Mobilizações: Identidade e Participação na Gestão de Iniciativas Museológicas Comunitárias. Museologia e Patrimônio, Unirio | MAST, 10(2), 261-282..

Cezário, H. B. M.; Davel, E.; Sancho-Querol, L, Sancho, E. (2018). Desafios da Gestão Participativa no Museu de São Brás em Portugal. RAC, Rio de Janeiro, 22 (1), 138-162.

Cezário, H. B. M.; Davel, E. (2017). A Mobilização Cultural na Gestão de Museus: A Força da Participação Comunitária e da Identidade Territorial. Revista Museologia \& Interdisciplinaridade, 6(12), 84-104.

Cezário, H. B. M.; Davel, E. (2018). A Mobilização Museológica Técnica na Gestão de Museus Comunitários: A Força da Participação Comunitária e da Identidade Territorial. Revista Gestão \& Sociedade, no prelo.

Chagas, M.; \& Abreu, R. (2007) Museu da Maré: memórias e narrativas a favor da dignidade social. Revista Musas, 3, 130-152. 
Chagas, M.; \& Gouveia, I. (2014) Museologia Social: reflexões e práticas. Cadernos do CEOM, Chapeco, 27(41), 9-22.

Craib, I. (1998). Expiriencing Identity. London: SAGE Publications.

Cury, M. X. (2010). Novas perspectivas para a comunicação museológica e os desafios da pesquisa de recepção em museus. Actas do I Seminário de Investigação em Museologia dos Países de Língua Portuguesa e Espanhola, 1, 269-279.

Czarniawska, B.(2008). A Theory of Organizing. Cheltenham: Edward Elgar.

Davel, E.; Pimentel, F.; \& Dantas, M. (2016). Identidade Cultural de Territórios como Política de Gestão. Anais do Anais do XL ENANPAD - Encontro da Associação Nacional de Pós-Graduação e Pesquisa em Administração. Sauípe, Bahia.

Davel, E.; \& Vergara, S. C. (2005, mar). Desafios relacionais nas práticas de gestão e de organização. RAE-Revista de Administração de Empresas, São Paulo, 45(1), 10-13.

Davies, S. (2001) Plano Diretor. (Série Museologia, 1). São Paulo: Editora da Universidade de São Paulo, Fundação Vitae.

Desvallées, A.; \& Mairesse, F. (Eds.) (2013). Conceitos-chave de Museologia. São Paulo: Comitê Brasileiro do ICOM, Pinacoteca do Estado, Secretaria de Estado da Cultura.

Diegues, Antonio C. S.(1992) Desenvolvimento sustentável ou sociedades sustentáveis - da crítica dos modelos aos novos paradigmas. São Paulo em Perspectiva, 6 (1/2), 22-9. Dessein, J.; Soini, K.;

Fairclough, G.; \& Horlings, L. (eds) (2015). Culture in, for and as Sustainable Development. Conclusions from the COST Action IS1007 Investigating Cultural Sustainability. University of Jyväskylä, Finland.

Fischer, T. M., \& Melo, V. P. (2004). Organizações e interorganizações na gestão do desenvolvimento territorial. Organizações e sociedade. Salvador: EAUFBA, 11.

França Filho, G. C. (2004). Para um olhar epistemológico da administração: problematizando o seu objeto. A administração política como campo do conhecimento. São Paulo-Salvador: Edições Mandacaru.

Fopp, M. (1997). Managing Museums and Galleries. London: Routledge.

Genoways, H. H.; Ireland, L. M. (2003). Museum Administration: an introduction. Walnut Creek, CA: AltaMira Press.

Gubrium, J. F., \& Holstein, J. A. (2009). Analyzing narrative reality. Thousand Oaks: Sage Publications.

Hall, S. (2006). Identidade Cultural na Pós-Modernidade. Rio de Janeiro: DP\&A Editora.

Hatch, M. J. (1993, oct). The Dynamics of Organizational Culture. The Academy of Management Review, 18(4), 657-693. 
Holland, D.; Lachicotte, W. J.; Skinner, D.; \& Cain, C. (1998). Identity and Angency in Cultural Words. Cambridge: Harvard University Press.

Hosking, D.; \& Fineman, S. (1990). Organizing processes. Journal of Management Studies, 27 (6), 583-604.

Ibram. (2016). Histórico do Programa Pontos de Memória. Disponível em: <http://www.museus.gov.br/acessoainformacao/acoes-e-programas/pontosdememoria/programa-pontos-de-memoria/>. Acesso em 5 de março de 2016. Lefebvre, H. (2000). La production de l'espace. Paris: Éditions Anthropos. Lersch, T. M.; \& Ocampo, C. C.(2009). Manual para la creación y desarrollo de museos comunitarios. Fundación Interamericana de Cultura y Desarrollo (ICDF). Bolivia: Artes Graficas Sagitario Srl.

Lord, B.;\& Lord, G. D. (2005). Manual de gestión de museos. Barcelona: Ariel.

Ma, J. F.(2014) Se a Administração é Ciência, qual é o seu Objeto de Estudo? Anais do VIII Encontro de Estudos Organizacionais da ANPAD-ENEO. Rio Grande do Sul, Gramado.

Machado, R. F. (2013). Um olhar etnográfico sobre a reconstituição da memória social de Matarandiba-BA. (Mestrado em Antropologia) - Faculdade de Filosofia e Ciências Humanas. Universidade Federal da Bahia, Salvador, BA.

Maitlis, S. (2012). Narrative analysis. In G. Symon \& C. Cassell (Eds.), Qualitative organizational research: core methods and current challenges. Los Angeles: Sage Publications.

Mason, T. (2004). Gestão Museológica: Desafios e Práticas. São Paulo: Editora da Universidade de São Paulo.

Mintzberg, H. (1995). Estrutura e dinâmica das organizações. Lisboa: Publicações Dom Quixote.

Moutinho, M. (1993). Sobre o Conceito de Museologia Social. Cadernos de Sociomuseologia, 1(1), 7-9.

Moutinho, M. (2007). The informal Museology. Cadernos de Sociomuseologia, 27, 183-188.

Priosti, O. M. (2010). Memória, comunidade e hibridação: Museologia da Libertação e estratégias de resistência. (Doutorado em Memória Social) Centro de Ciências Humanas e Sociais, Universidade Federal do Estado do Rio de Janeiro.

Priosti, O. M.; \& Mattos, Y. (2007). Caminhos e percursos da museologia comunitária. Cadernos de Sociomuseologia, 28, 1-16.

Rattner, H. (1999) Sustentabilidade - uma visão humanista. Ambiente \& Sociedade, Ano II, n. 5, p.233-40.

Riessman, C. K. (2008). Narrative Methods for the human sciences. Los Angeles: Sage Publications. 
Sancho-Querol, L. (2016). El Patrimonio Cultural Inmaterial y la Sociomuseologia: estudio sobre inventarios. Cadernos Sociomuseologia, Nova Série: Estudos Posgraduados, 1. Lisboa: ULHT.

Sancho-Querol, L.; \& Sancho, E. (2015). How can museums contribute to social and cultural change? In Jensen, J. T.; Lundgaard, I. B. (Coord.) Museums: Citizens and sustainable solutions. Denmark: Danish Agency for Culture, p. 212-231.

Santos, M. C. (2008). Encontros Museológicos: reflexões sobre a museologia, a educação e o museu (Coleção Museu, Memória e Cidadania). Rio de Janeiro: MINC/IPHAN/DEMU.

Santos, M. (2000). O Papel Ativo da Geografia - Um Manifesto. Revista Território. Rio de Janeiro, V(9), 103-109.

Santos, T. da C.E S. S. (2005) As diferentes dimensões da sustentabilidade em uma organização da sociedade civil brasileira: o caso do GAPA - Bahia. (Mestrado em Administração) - Núcleo de Pós-Graduação da Escola de Administração da Universidade Federal da Bahia.

Saquet, M., \& Briskievicz, M. (2009). Territorialidade e identidade: um patrimônio no desenvolvimento territorial. Caderno Prudentino de Geografia, 1(31), 3-16.

Scheiner, T. C., \& Brulon Soares, B. (2009). A ascensão dos museus comunitários e os patrimônios comuns: um ensaio sobre a casa. E-book do ENANCIB. João Pessoa: Ideia.

Tude, J. M., Mello, L. M., \& Vasconcelos, Y. (2009). Captação de recursos para projetos. Curitiba: IESDE Brasil.

Varine-Bohan, Hugues de. (2012). As Raízes do Futuro: o patrimônio a serviço do desenvolvimento local. Porto Alegre: Medianiz.

Varine-Bohan, H. d. (2013). As Raízes do Futuro: o patrimônio a serviço do desenvolvimento local (Horta, Maria de Lourdes Parreira. Trad.) Porto Alegre: Medianiz.

Varine-Bohan, H. d. (2014). O museu comunitário como processo continuado. Cadernos do CEOM , 27(42), 25-35.

Watson, T. J. (2005). Organização e trabalho em transição: da lógica "sitêmicocontroladora" à lógica "processual-relacional". Revista de Administração de Empresas, 45(1), 14-23.

Yin, R. K. (2010). Estudo de caso: planejamento e métodos. Porto Alegre: Bookman.

\section{Autores}

Hilda Bárbara Maia Cezário

Museu do Traje, São Brás de Alportel, Portugal

hbarbaramaia@gmail.com 
Graduada em Museologia pela Universidade Federal da Bahia (2011). Mestre em Desenvolvimento e Gestão Social pelo Centro Interdisciplinar de Desenvolvimento e Gestão Social da Universidade Federal da Bahia (2016). Possui experiência na área museológica, com atuação na gestão de museus e de ações socioculturais e educativas em museus. Áreas de interesse em pesquisa: Museologia Social com enfoque na gestão de museus; Teoria Museológica e Educação Museal; Administração com enfoque em autogestão, gestão compartilhada, organizações e interorganizações, identidade e cultura organizacional; Desenvolvimento territorial com enfoque em temáticas como sustentabilidade, interações entre o global e o local, identidade cultural e participação cidadã. Vice-presidente da Associação de Amigos do Museu do Alto Sertão da Bahia (2016-2018) e faz parte da Comissão Gestora da Rede de Educadores em Museus da Bahia desde 2012.

\section{Eduardo Davel}

Escola de Administração, Universidade Federal da Bahia, Brasil

Davel.eduardo@gmail.com

Professor na Escola de Administração da Universidade Federal da Bahia. Pesquisador do CIAGS - Centro Interdisciplinar de Desenvolvimento e Gestão Social (UFBA). Pós-doutorado em Administração pela Nova School of Business and Economics da Universidade Nova de Lisboa (Portugal). Ph.D. em Administração pela École des Hautes Études commerciales de Montreal (Canadá). Pesquisador visitante na Graduate Faculty of Political and Social Science da New School for Social Research (New York, EUA). Editor da RIGS Revista Interdisciplinar de Gestão Social. Pesquisa e publica sobre empreendedorismo cultural, gestão do processo criativo, ensino, metodologia, aprendizagem, cultura e estética nas organizações. 